tions receiving more incentives than do ordinary professors.

Having described a generalized image of Scandinavian higher education, it is, however, fair to end these reflections by pointing to some differences within the region. Even though the trends of the 1990s are common for all the countries, there are differences in pace and level of development.

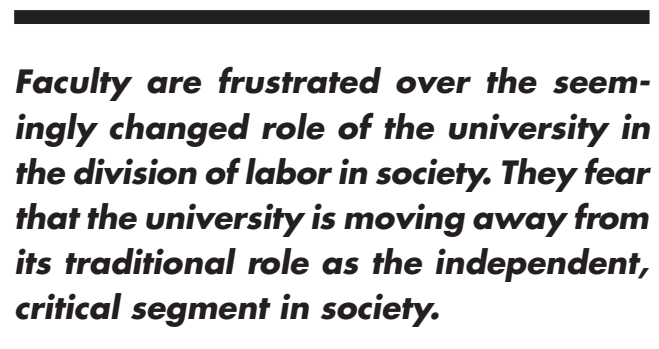

What is often termed the "international" or "American" development of higher education started first in Sweden, followed by Finland. These two countries have undergone the most dramatic changes, and their economic situation has been one important reason. First in harmonizing their higher education structures, they have been more eager to go international in their publishing work. The other group-Denmark, Norway and Iceland-has been more "conservative," maintaining strong institutional autonomy in relation to the state. Norway is beginning the process of internationalization but can, with its oil money, obviously afford to move slowly. For Denmark and Norway the "student rebellion" and extreme democratization of governing bodies in the 1970s, seemed to have reinforced university conservatism toward the state's needs.

Looking at the research function of the institutions, Sweden and Finland, more than the others, are characterized by efficient research, hierarchical research groups, external financing, competition, lower job security (tenure), and a willingness to adapt to changing conditions. The states have taken a stronger governing role than in the three other countries, where the institutions have been allowed greater independence from the state. There has been no research policy for the institution as a whole, rather the attitude has been, "every professor-his own research policy." They have been allowed fairly quiet, individually tenured lives. The often painful change now is in the "American" direction.

An assumption is that in the future, Scandinavian higher education will become increasingly homogenous in policies and organization, and, at the same time, more like the dominant international pattern.

\section{Higher Education in Thailand: Traditions and Bureaucracy}

\section{Sakda Prangpatanpon}

Sakda Prangpatanpon is associate professor and chair, Department of Foundations of Education, Burapha University, Bangsaen, Chonburi 20131, Thailand. He holds a Ph.D. degree from Boston College. Fax: 38-391-043.

$\mathrm{H}$ igher education as a government function is relatively new in Thailand. The first university, Chulalongkorn University, was founded in 1917; a second university was established in 1933; and three more were founded in 1943. These five universities, all located in Bangkok, were established primarily to train personnel for government service. In the 1960s, three public universities were established outside the capital, one each for the north, the northeast, and the south. Private colleges also appeared around this time, and in 1969 a bill was enacted to govern the establishment and operation of private institutions of higher learning. Additional colleges and universities were founded thereafter, all of which followed the model of the older institutions in terms of mission, organization, and administration.

\section{Often what passes for university edu- cation is little more than a capacity for passing successive examinations, re- gardless of whether there has been in- tellectual growth.}

Today, there are 65 public and private universities and colleges in Thailand under the supervision of the Ministry of University Affairs, and an additional 150 other educational institutions offering various vocational degree courses that come under supervision of the Ministry of Education and other ministries. Therefore, in terms of numbers of institutions, higher education in Thailand has come a long way since its modest beginning. However, in terms of quality, there is still room for improvement, even at the "older" universities. Recent issues and problems in Thai higher education include: unclear and ambiguous educational aims, inadequate financing, inability to recruit enough qualified lecturers, insufficient numbers of graduates in science and technology to serve the country's economic development, and an outdated administrative system. Many of these issues and problems are related to the culture and tradition 
of the universities and Thai society generally. Without proper adaptation and adjustment of the country's culture and traditions, the problems will be difficult to overcome.

\section{Teaching and Learning}

Academically and administratively, universities in Thailand are based on a system of faculties - each under a separate dean, as in the United Kingdom. Teaching and course organization, on the other hand, are similar to the American system, with a credit course system being used. However, the relationship between professors and students follows the Thai school approach rather than any foreign model, which has a strong influence on students' attitudes and academic standards. Rites and rituals in the university reinforce this approach.

\section{Academically and administratively, uni- versities in Thailand are based on a sys- tem of faculties-each under a separate dean, as in the United Kingdom. Teach- ing and course organization, on the other hand, are similar to the American system, with a credit course system be- ing used.}

For example, Thai universities still practice the tradition of paying homage to teachers. In the old days, teachers did not receive any pay and taught their students out of kindness, so students were grateful and would hold a ceremony every year to show their great respect for the teachers. Now, even though teaching is a paid profession, this tradition is still followed at all levels of education. At the beginning of each academic year every university conducts an elaborate ceremony to honor teachers-a kind of initiation rite for university students. In addition, undergraduate students still wear uniforms and are expected to attend classes regularly. Even graduate students, who are not required to wear uniforms, often choose to wear them. Professors in public universities have uniforms too-and though they do not wear them regularly, they are proud to have their pictures taken in full uniform. As a result, the mental attitudes of students and professors stress conformity rather than developing creative thinking and intellectual development. Moreover, most professors use lecturing as the main form of instruction, and students rarely argue or criticize in class since they are not raised to have this kind of participative experience.
Thai university students spend many more hours in class (often between 20 and 25 hours per week) than the typical American student. It is this high proportion of class contact hours, as well as the traditional respect for teachers, that explains the relationship between professors and students and the lack of self-learning activities among students. Most Thai students are used to authoritarian practice, and are willing to accept what their professors say without question because they see the university as a continuation of their traditional schooling in which they receive information submissively and passively.

\section{The Purpose of Education}

Many Thais still believe in the traditional purpose of a university education, namely job training. Students, as well as parents, look to university simply as a place to help them gain professional and material advancement-as a result, they will do whatever they can to get into a university and obtain a degree. The admissions process to public universities, which are generally more prestigious than the private universities, is quite rigorous, and favors children of professional parents and businessmen and those from the Bangkok metropolitan area. These students can afford the best tutorial schools to pass examinations for the best high schools, and later to pass the national entrance examination for university. Once in the university, students are only interested in graduating as soon as possible, and are prepared to accept the status quo of the hierarchical system. Students are also liable to be more materialistic and selfish because of the privileged environment in the university.

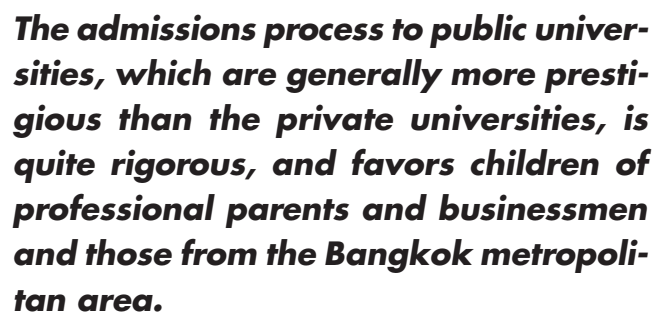

Because of their historical evolution and government control, most university programs have been narrowly vocational, training students for specific professions. The result of this vocational focus has been the absence of any real concept of "higher" education, and liberal or general education. The only subjects that matter to students, and to many professors as well, are those in their major disciplines, because they believe that these subjects will give 
them the skills for future employment. Therefore, most, if not all, Thai universities do little to enrich the minds, ennoble the character, and expand the horizons of students. They also have not done enough to develop students' compassion and sensitivity to their fellow human beings. The failure to integrate knowledge in various disciplines keeps students from gaining a broader understanding and preparing themselves for a more global society. Often what passes for university education is little more than a capacity for passing successive examinations, regardless of whether there has been intellectual growth.

\section{The Administrative System}

Each public university in Thailand was created by special legislation, and is considered to be an extension of the government. All teaching and nonteaching staff are referred to as "government officials" rather than "public servants," and are thought to work for the "government" and not the "public." As a result, many staff still have an aristocratic mentality, and the university acts like an "ivory tower" and does not respond enough to local needs and conditions. Moreover, the university and its staff are under government regulations and civil service rules, and bureaucratic red tape can cause delays in work. Administrative promotions and salary increases often depend more on cooperation with one's superiors and length of service than on teaching quality or research work. In addition, salaries at public institutions are tied to the civil service scale and are much lower than those in the private sector.

\section{While there have been complaints about salaries, inadequate financing, and lack of autonomy, so far none of the exist- ing public universities have pushed hard enough to leave the bureaucratic sys- tem.}

While there have been complaints about salaries, inadequate financing, and lack of autonomy, so far none of the existing public universities have pushed hard enough to leave the bureaucratic system. Because of the special relationship between the monarchy and the people, the Thais consider serving in the "Royal Affairs" (as the government service is called) a very honorable and prestigious act. They are the "King's men," and receive royal decoration when they reach certain levels of positions or have served for a number of years. The King or a member of the Royal Family presides over the annual graduation ceremony to bestow degrees on graduates of government universities only. Therefore, university professors and staff want to keep all these privileges and job security, despite their wish to be out of government control.

\section{Recent Developments}

Suranaree University of Technology, established in 1990 and located in the northeastern part of Thailand, became the first public university to operate outside the control of the central bureaucracy. It operates under an autonomous administrative system, with financial support from the government in the form of block grants. The university council has full powers to make decisions and set its own rules, governing such things as academic staff, salary scale, curricula, and endowments. Its staff are not considered government officials but are hired in the same way as staff in private businesses and receive periodic performance reviews and higher salaries. However, students at Suranaree University still wear uniforms and practice the custom of paying homage to teachers in the traditional way. Other universities are closely watching the system at Suranaree University and some plan to seek a similar arrangement.

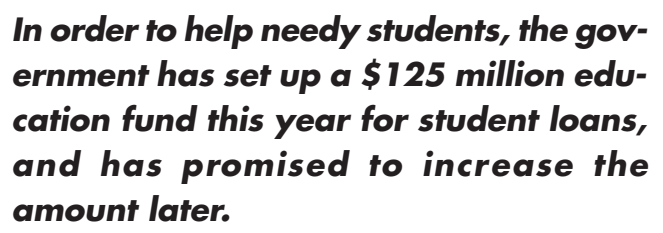
ernment has set up a $\$ 125$ million education fund this year for student loans, and has promised to increase the amount later.

In order to help needy students, the government has set up a $\$ 125$ million education fund this year for student loans, and has promised to increase the amount later. Academically, most universities now require students to take general education courses, and have plans to instill ethical values in students as well as to make the higher education curriculum more internationalized. Tapping into students' interests and personal potential is a priority. Professors are urged to make teaching and learning more relaxed and democratic. The Ministry of University Affairs is now working on quality assurance and accountability systems for all universities. It is also working with the Ministry of Education to develop a better university admissions system, one that will place less emphasis on examination performance and ensure fairness to all. 